\title{
EFFECT OF ULTRAVIOLET RADIATION ON STRUCTURAL PROPERTIES OF NANOWIRES
}

\author{
Raminder Kaur \\ Department of Basics and Applied Sciences, Punjabi University, Patiala (Pb.), INDIA
}

\begin{abstract}
Copper nanowires were prepared through electrochemical template synthesis using Nucleopore polycarbonate membranes having nominal pore sizes of $800 \mathrm{~nm}$ and $15 \mathrm{~nm}$ diameter. The $800 \mathrm{~nm}$ and $15 \mathrm{~nm}$ nanowires thus grown were viewed under SEM and TEM respectively, while their FCC crystallographic structure was confirmed through $X$-ray and electron diffraction patterns. The X-ray diffraction peaks indicated strong texturing for (200). The texturing was found to reduce significantly upon exposure to ultraviolet radiation.
\end{abstract}

\section{KEYWORDS}

Nanowires, Template Synthesis, Texturing, Ultraviolet.

\section{INTRODUCTION}

Nanofabrication techniques offer remarkable miniaturization potential, which is essential for further growth of the electronics industry. While refinements in various photolithography and vapour deposition techniques have been responsible for the tremendous progress made by this industry over the past half century, further development in this field calls for various technological breakthroughs, including further miniaturization of the metal interconnects. Owing to its favourable mechanical, thermal and electrical properties, along with low electromigration problems, copper has been gaining popularity over aluminium as an electric interconnect material in the semiconductor industry [1]. Copper nanowires hold the potential to serve as interconnects in futuristic nanoelectronic devices [2].

Polycrystalline materials, such as copper consist of many small crystallites or grains, compactly assembled to form the bulk material. The intrinsic properties, viz. piezoelectric constant, elastic coefficients, thermal coefficients etc. are usually anisotropic within a crystallite, i.e., the values of these properties are different along different crystallographic directions. At macro scale, these properties will follow isotropic distribution if the bulk material contains a very large number $\left(\sim 10^{10}\right)$ of grains with equal probability of orientation in any direction, but will turn out to be anisotropic in case of strongly textured materials [3,4]. Preferred crystallographic orientation, or texture, usually results from the history of material processing. As a consequence thereof, the properties important from engineering perspective, as well as their degree of isotropy are governed to a great extent by the underlying crystallographic structure [5]. The effect of any bias in crystal orientation on material properties would be much more prominent in case of nano-scale components owing to their small overall dimensions and associated much smaller number of crystallites. Accurate measurement of texture is therefore essential for ascertaining the performance of fabricated nanocomponents. Though, an accurate measurement of texture requires specialized equipment [6], but the present work involves only preliminary investigations using a conventional powder X-ray diffractometer [7]. 


\section{Characterization AND ANALYSIS}

The fabrication of copper nanowires was carried out through electrochemical deposition of elemental copper into the pores of Nuclepore polycarbonate membrane, which covered the cathode during the deposition process. Two different types of membranes, having pore diameters of $800 \mathrm{~nm}$ and $15 \mathrm{~nm}$, pore density of $10^{8} / \mathrm{cm}^{2}$ and $11 \mu \mathrm{m}$ thickness each were employed as templates. The layout design of the electrochemical cell, along with other relevant details of the technique can be referred from earlier work [8].

To start the fabrication process, the cell is filled with freshly prepared and filtered electrolyte, comprising of $2.5 \mathrm{~N}(200 \mathrm{~g} / \mathrm{l}) \mathrm{CuSO}_{4} .5 \mathrm{H}_{2} \mathrm{O}$ dissolved in double-distilled, de-ionized water at room temperature $\left(35^{\circ} \mathrm{C}\right)$. Current density of 8 to $10 \mathrm{~mA} / \mathrm{cm}^{2}$ was kept during deposition process.

The morphological examination of the 800nm diameter wires was done under Joel, JSM 6100 scanning microscope at an accelerating voltage of $20 \mathrm{kV}$ (refer Figure 1).

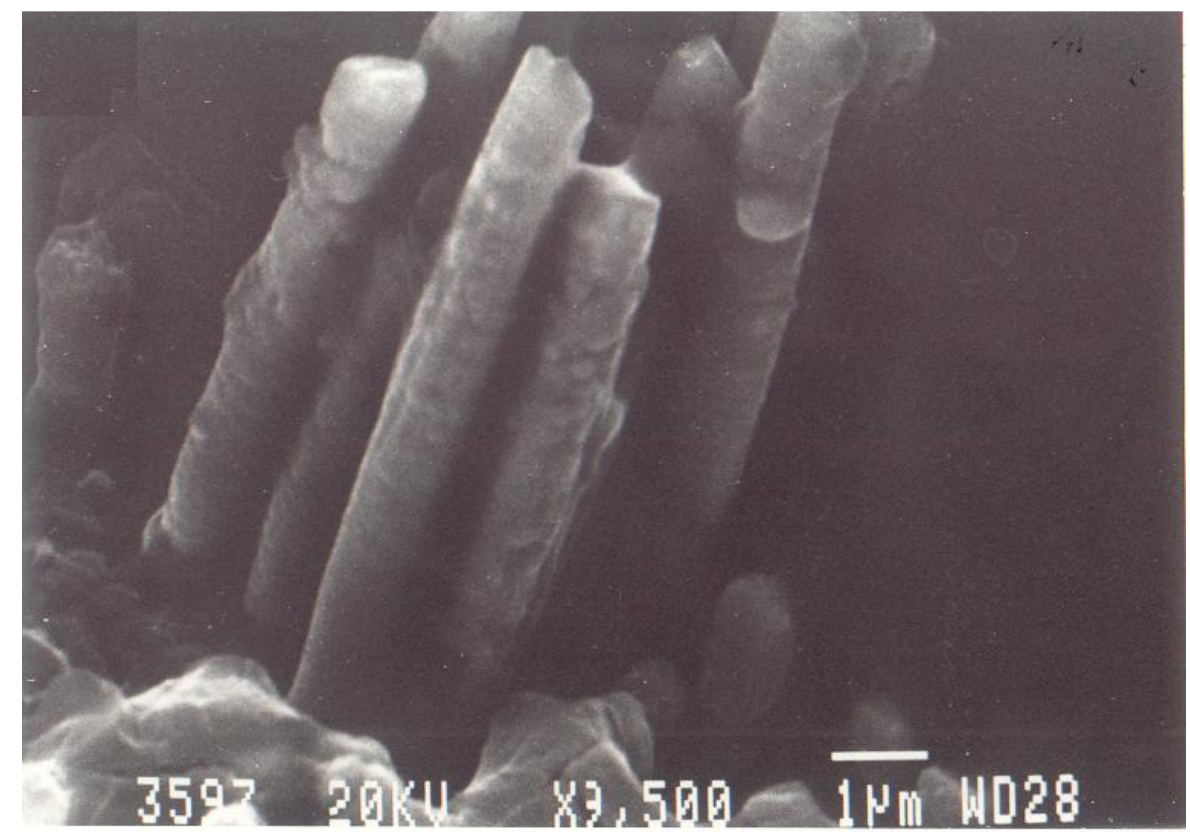

Figure 1. SEM image showing 800nm copper nanowires

Owing to their smaller size, the $15 \mathrm{~nm}$ copper nanowires were viewed under FEI Tecnai $20 \mathrm{G} 2 \mathrm{~S}$ TWIN transmission electron microscope, operated at 200kV (Refer Figure 2). The transmission high energy electron diffraction (THEED), or commonly known as selected area electron diffraction (SAED) pattern was also obtained in the transmission electron microscope and is shown Figure 3. 


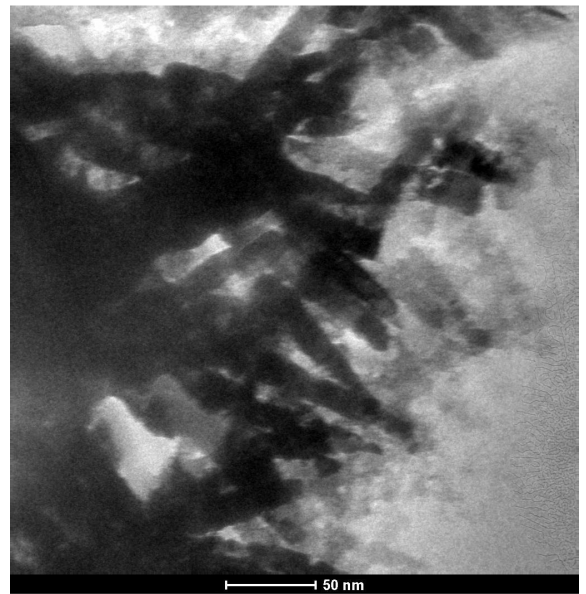

Figure 2 TEM image showing 15nm copper nanowires

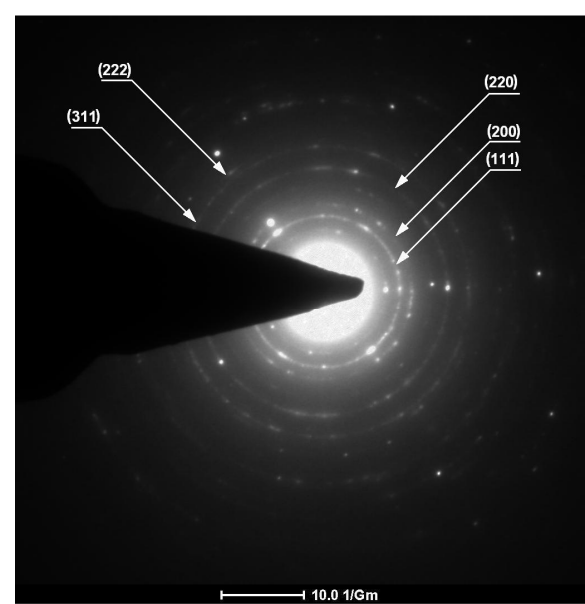

Figure 3. SAED pattern for $15 \mathrm{~nm}$ copper nanowires

In order to carry out X-ray diffraction analysis of the deposited nanowires, the polycarbonate membranes containing nascent nanowires were peeled-off from the cathode and mounted in specimen holder of D/Max Rint 2000 Rigaku (Tokyo) X-ray diffractometer. The X-ray diffractograms obtained for $800 \mathrm{~nm}$ and $15 \mathrm{~nm}$ nanowires are shown in Figure 4 and Figure 5 respectively, while the application of extinction rules for identification of peaks is summarised in Table 1. As can be inferred from these diffractograms, both types of nanowires exhibited strong texturing for (200) plane.

Table 1: Identification of diffraction peaks

\begin{tabular}{|c|l|l|l|c|}
\hline $\mathbf{2 \theta}$ & \multicolumn{1}{|c|}{$\sin ^{2} \boldsymbol{\theta}$} & \multicolumn{1}{c|}{ Ratios } & Normalized Ratios & Lattice Planes \\
\hline 43.26 & 0.1359 & 1 & 3 & $(111)$ \\
\hline 50.28 & 0.1805 & 1.33 & $3.98 \sim 4$ & $(200)$ \\
\hline 73.98 & 0.3620 & 2.66 & $7.99 \sim 8$ & $(220)$ \\
\hline 89.84 & 0.4986 & 3.67 & $11.01 \sim 11$ & $(311)$ \\
\hline
\end{tabular}

Subsequent to recording of the X-ray diffractograms, the nanowires were irradiated with ultraviolet radiation for a period of 10 minutes using a pulsed nitrogen laser source having an output power of $10 \mathrm{~kW}$, emission wavelength of $337.1 \mathrm{~nm}$ and a pulse width of less than $10 \mathrm{~ns}$, which corresponds to an intensity of around $2 \times 10^{9} \mathrm{~W} / \mathrm{m}^{2}$ over the beam cross-section of $2 \times 3 \mathrm{~mm}$, while the wavelength corresponds to a photonic energy of $h c / \lambda=5.9 \times 10^{-19} \mathrm{~J}$ or $3.68 \mathrm{eV}$. This energy can cast various pyrolytic as well as photolytic effects, viz. localized heating of surface layers, degradation of polycarbonate membrane, in particular, by breaking the $\mathrm{C}-\mathrm{C}$ bonding, as the bond energy for these bonds is less than the energy of photons [9], formation of oxides or hydroxides over the regions exposed to atmosphere [10,11] and finally, in view of the high intensity of laser radiation, absorption of photons by electrons and subsequent localized rise in temperature, thereby paving the route for local recrystallization [12]. 
International Journal on Organic Electronics (IJOE) Vol.4, No.1/2/3/4, October 2015

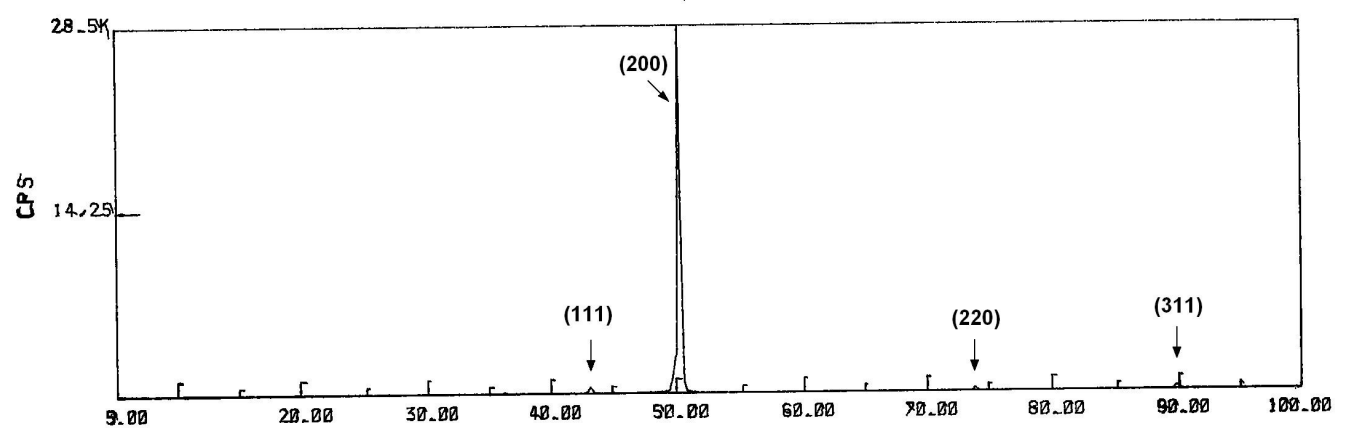

Figure 4. X-ray diffractogram of copper nanowires deposited in membrane having pore diameter of $800 \mathrm{~nm}$. (Before ultraviolet exposure)

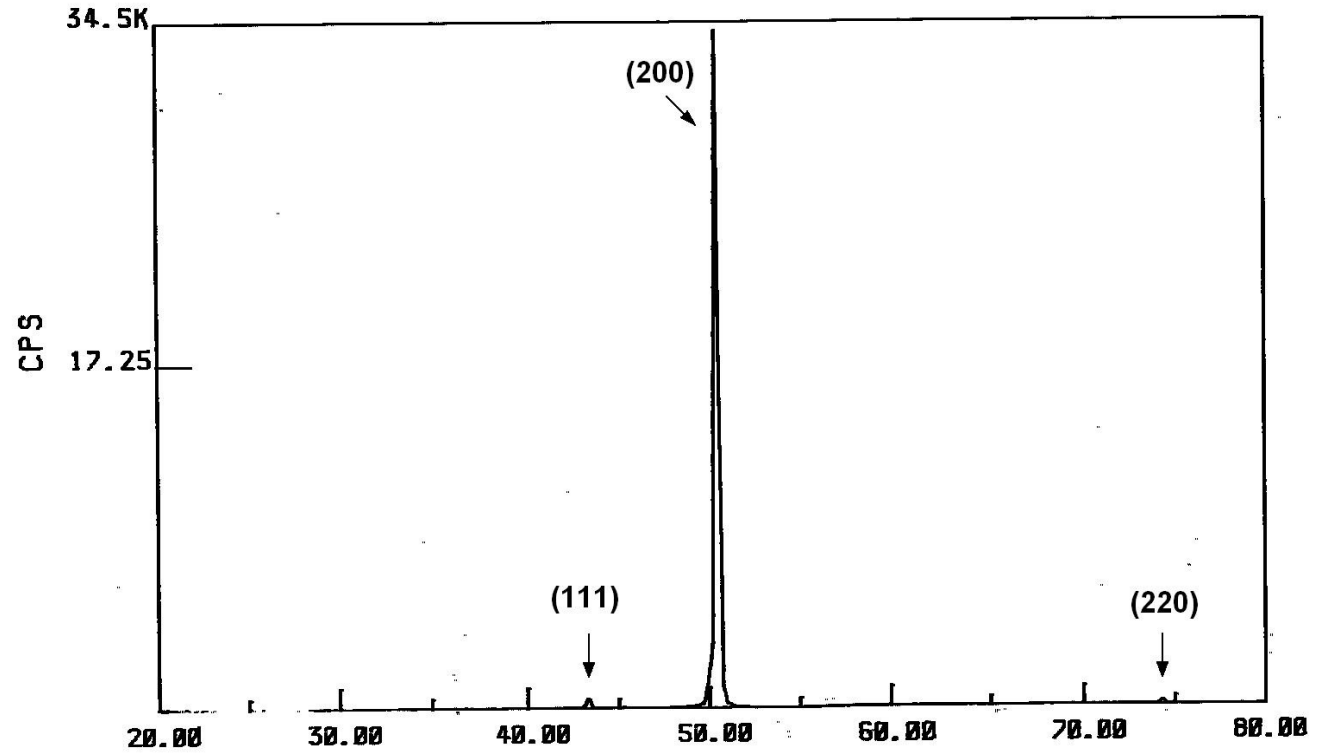

Figure 5. X-ray diffractogram of copper nanowires deposited in membrane having pore diameter of $15 \mathrm{~nm}$. (Before ultraviolet exposure)

In order to investigate the effect of exposure to ultraviolet radiation on the crystallographic structure of nanowires, the specimens thus irradiated were again mounted on X-ray diffractometer for diffraction analysis. The resulting diffractograms corresponding to $800 \mathrm{~nm}$ and $15 \mathrm{~nm}$ nanowires are shown in Figure 6 and. Figure 7 respectively. 


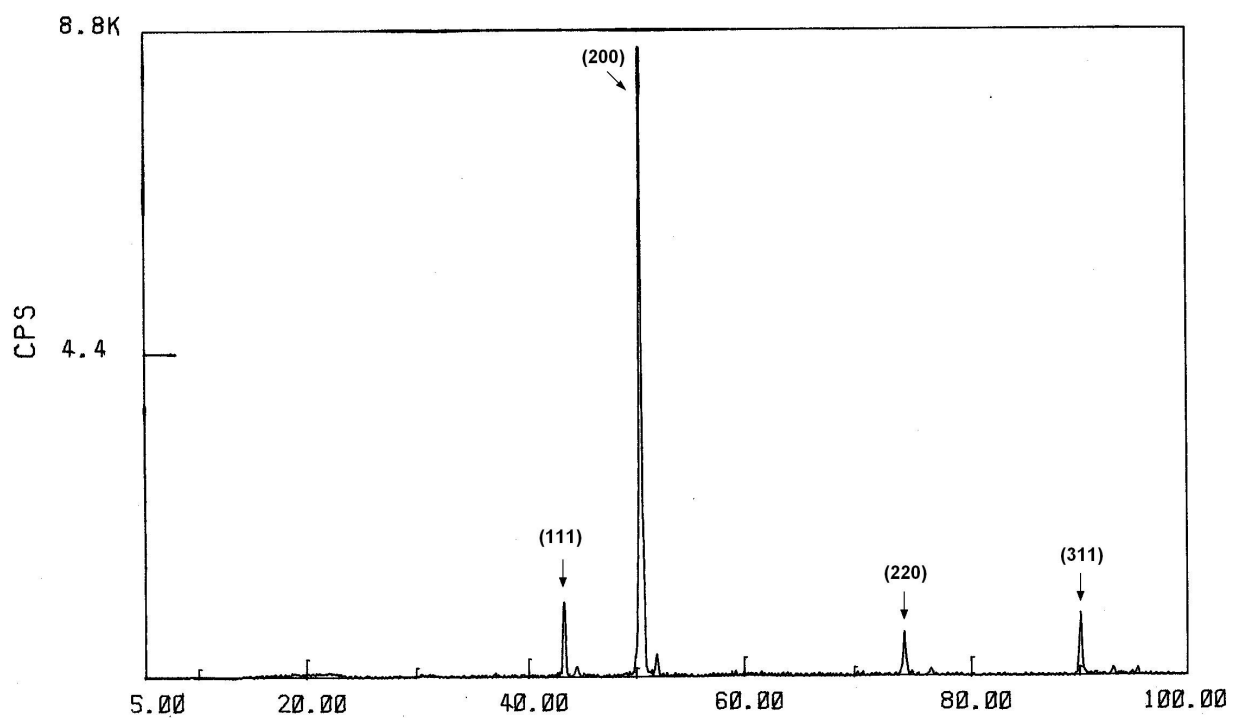

Figure 6. X-ray diffractogram of copper nanowires deposited in membrane having pore diameter of $800 \mathrm{~nm}$. (After ultraviolet exposure)

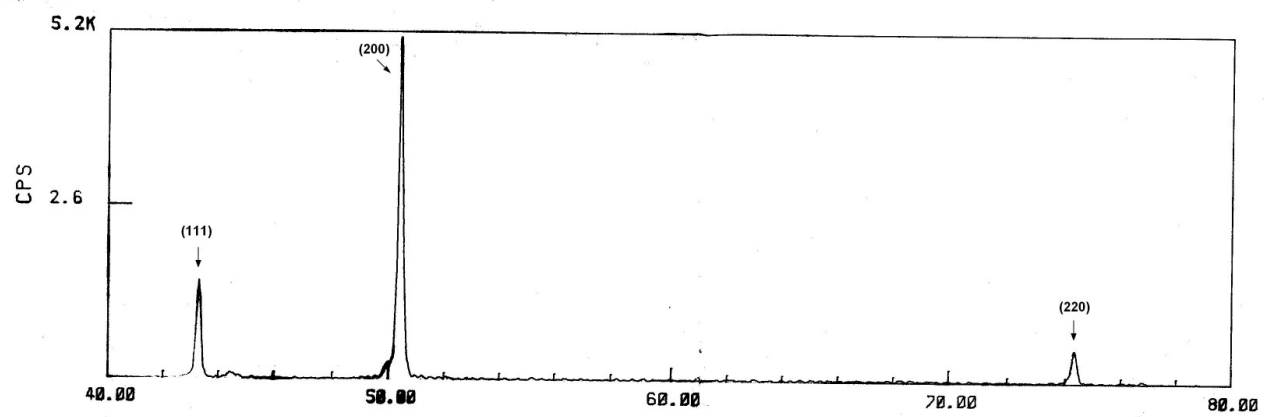

Figure 7. X-ray diffractogram of copper nanowires deposited in membrane having pore diameter of $15 \mathrm{~nm}$. (After ultraviolet exposure)

The diffractograms indicate a reduction in texturing of fabricated nanowires following exposure to ultraviolet radiation. The texture coefficients pertaining to each of the diffractograms presented above has been analysed for pole density $\left(P_{h k l}\right)$ using the relationship given below [13]:

$$
P_{h k l}=\frac{I_{h k l}}{I_{0 h k l}}\left[\frac{1}{n} \sum \frac{I_{h k l}}{I_{0 h k l}}\right]^{-1}
$$

Where $P_{h k l}$ is the texture coefficient of the plane specified by Miller Indices $(h k l)$; while $I_{h k l}$ and $I_{0}$ ${ }_{h k l}$ are the specimen and standard intensities respectively for the given peak and $n$ refers to the total number of diffraction peaks being taken into consideration. The observations pertaining to texture coefficients exhibited by fresh and ultraviolet irradiated specimens are summarized in Table 2. 
Table 2: Texture coefficients of $\mathrm{Cu}$ nanowires before and after exposure to ultraviolet radiation

\begin{tabular}{|c|c|c|c|c|}
\hline State: & \multicolumn{2}{|c|}{ Before UV exposure } & \multicolumn{2}{c|}{ After UV exposure } \\
\hline Pore-size: & $\mathbf{8 0 0} \mathbf{~ n m}$ & $\mathbf{1 5} \mathbf{~ n m}$ & $\mathbf{8 0 0} \mathbf{~ n m}$ & $\mathbf{1 5} \mathbf{~ n m}$ \\
\hline $\boldsymbol{h} \boldsymbol{k} \boldsymbol{l}$ & \multicolumn{3}{|c|}{ Texture Coefficient } \\
\hline$(111)$ & 0.035 & 0.031 & 0.205 & 0.488 \\
\hline$(200)$ & 2.916 & 2.936 & 2.518 & 1.997 \\
\hline$(220)$ & 0.049 & 0.033 & 0.276 & 0.516 \\
\hline Std. Deviation & $\mathbf{1 . 6 5 8}$ & $\mathbf{1 . 6 7 7}$ & $\mathbf{1 . 3 1 5}$ & $\mathbf{0 . 8 6 3}$ \\
\hline
\end{tabular}

The data presented reveals considerable reduction in texturing for both the specimens upon exposure to ultraviolet radiation, as confirmed by corresponding values of standard deviation. The observed changes in peak intensities are more than the general inherent variability on the order of 2 percent for the powder X-ray diffraction technique [14]. Such a modification in crystal structure of polycrystalline metals is known to require accumulation of a considerable amount of energy and would normally occur during heat-treatment or extensive mechanical straining of the material $[15,16]$.

The observed phenomenon can be explained on the basis of dynamics of ultrafast melting of metals under the influence of high intensity pulsed radiation. The quasi-free conduction-band electrons in metals play a leading role in absorption of electromagnetic radiation incident on the metal surface. The absorption of photon by a lattice electron, followed by an increase in kinetic energy of the latter is known as inverse Bremsstrahlung [17]. The electrons form an expanding plasma as the laser pulses propagate into the metal surface. The intensity of radiation employed in the present work lies well within the linear resonance absorption range, which extends up to $10^{16}$ $\mathrm{W} / \mathrm{cm}^{2}$ [18]. The typical ranges for electron collision frequency $(\gamma)$ and plasma frequency $\left(\omega_{p}\right)$ for metals are generally taken to be $10^{13}-10^{14} \mathrm{~Hz}$ and $10^{15}-10^{16} \mathrm{~Hz}$ respectively, while the wavelength of ultraviolet radiation corresponds to a frequency of $\omega=8.9 \times 10^{14} \mathrm{~Hz}$, which corresponds to the case of large absorption, as $\gamma<\omega<\omega_{p}$ [19]. The absorbed energy is subsequently converted into heat through electron-phonon interactions [20]. The high intensity of laser beam, coupled with its pulse duration of a few nanoseconds can cause localized heating to above melting point, thereby leading to partial re-crystallization [13,21], which in turn serves to reduce anisotropy of the material and is therefore, thought to be responsible for the observed reduction in texturing.

\section{CONCLUSIONS}

Nanowires of copper were deposited successfully into the nanopores of Nuclepore polycarbonate membranes having pore diameters of $800 \mathrm{~nm}$ and $15 \mathrm{~nm}$. All the specimens prepared at room temperature $\left(30^{\circ} \mathrm{C}\right)$ exhibited a strong texturing for (200) plane, which got reduced considerably upon exposure to pulsed ultraviolet radiation. The observed reduction in texturing is attributed to be due to localized, ultrafast melting and recrystallization. 


\section{REFERENCES}

1) T. Muppidi and D.P. Field, (2003) "Effect of barrier layers on the texture and microstructure of Copper films" MRS Proceedings - Symposium E - Materials, Technology and Reliability for Advanced Interconnects and Low-k Dielectrics, vol. 766, pp 241-250

2) W.H. Xu , L. Wang , Z. Guo , X. Chen , J. Liu and X.J. Huang, (2015) "Copper Nanowires as nanoscale Interconnects: Their Stability, Electrical Transport, and Mechanical Properties" ACS Nano, vol. 9 (1), pp. 241-250.

3) K. Liu, C. Chien, P. Searson and K. Yu-Zhang, (1998) "Structural and magneto-transport properties of electrodeposited bismuth nanowires" Applied Physics Letters, vol. 73, no. 10, pp. 1436.

4) J. Heremans, C.M. Thrush, Y-M. Ling, S. Cronin, Z. Zhang, M.S. Dresselhaus and J.F. Mansfield, (2000) "Bismuth nanowire arrays: Synthesis and galvanomagnetic properties", Phys. Rev. B vol. 61, pp. 2921.

5) M.S. Dresselhaus, Y.M. Lin, O. Rabin, M.R. Black and G. Dresselhaus, (2004) "Nanowires" Handbook of Nanotechnology. Berlin: Springer, pp. 99-145.

6) C. Barrett and T. Massalski, (1980) "Structure of metals". Oxford: Pergamon Press, pp. 154 - 177.

7) M.D. Vaudin, M.W. Rupich, M. Jowett, G.N. Riley Jr. and J.F. Bingert, (1998) "A method for crystallographic texture investigations using standard X-ray equipment" Journal of Materials Research,. Vol. 13, Issue 10, pp. 2910-2919.

8) R. Kaur, N.K.. Verma, S. Kumar and S.K. Chakarvarti, (2006) "Fabrication of copper microcylinders in polycarbonate membranes and their characterization", Journal of Materials Science, vol. 41, no. 12, pp. 3723-3728.

9) W.M. Steen and J. Mazumder, (2010) "Laser Material Processing", Springer-Verlag London Limited, pp 373.

10) J.R. Vig, (1985) "UV/ozone cleaning of surfaces" Journal of Vacuum Science and Technology A, vol. 3, pp 1027-1034.

11) R. Kaur, N.K. Verma and S.K. Chakarvarti (2007) "Morphological, structural and optical characterization of nickel nanostructures" Journal of Materials Science, vol. 42, pp 5629-5631.

12) J. Meijer, (2004) "Laser beam machining (LBM), state of the art and new opportunities", Journal of Materials Processing Technology, vol. 149, pp. 2-17.

13) I. Iordanova, V. Antonov and S. Gurkovsky, (2002) "Changes of microstructure and mechanical properties of cold-rolled low carbon steel due to its surface treatment by Nd:glass pulsed laser", Surface and Coatings Technology, vol. 153, pp. 267-275.

14) D.E. Kretschmann, H.A. Alden and S. Verrill (1997) "Variations of microfibril angle in loblolly pine: comparison of iodine crystallization and x-ray diffraction techniques", Proceedings of the IAWA/IUFRO International Workshop on the Significance of Microfibril Angle to Wood Quality, Westport, New Zealand, pp. 157

15) S. Sato, T. Yoshimura, N. Yamada, K. Wagatsuma and S. Suzuki, (2011) "Evolution of texture and dislocation distributions in high-ductile austenitic steel during deformation" ICDD Denver X-ray Conference (DXC) on Applications of X-ray Analysis, JCPDS International Centre for Diffraction Data, pp. 37-43.

16) S. Aubry, K. Kang, S. Ryu and W. Cai, (2011) "Energy barrier for homogeneous dislocation nucleation: Comparing atomistic and continuum models" Scripta Materialia, vol. 64, pp. 1043-1046

17) J. F. Seely, (1974) "Quantum Theory of Inverse Bremsstrahlung Absorption and Pair Production" Laser Interaction and Related Plasma Phenomenon, pp. 835-847.

18) J. C. Kieffer, P. Audebert, M. Chaker, J. P. Matte, H. Pépin, T. W. Johnston, P. Maine, D. Meyerhofer, J. Delettrez, D. Strickland, P. Bado, and G. Mourou, (1989) "Short-Pulse Laser Absorption in Very Steep Plasma Density Gradients” Physical Review Letters, vol. 62, pp. 760-763.

19) C. J. Nonhof (1988) “Material process with Nd-lasers". Electrochemical Publications Ltd. 
International Journal on Organic Electronics (IJOE) Vol.4, No.1/2/3/4, October 2015

20) A.S. Sandhu, A.K. Dharmadhikari and G.R. Kumar, (2005) "Time resolved evolution of structural, electrical, and thermal properties of copper irradiated by an intense ultrashort laser pulse" Journal of Applied Physics, vol. 97, pp. 023526-1-023526-5.

21) V. Antonov, I. Iordanova and S. Gurkovsky, (2002) "Investigation of surface oxidation of low carbon sheet steel during its treatment with Nd: Glass pulsed laser" Surface and Coatings Technology, vol. 160, pp. 44-53.

\section{Author}

Dr. Raminder Kaur is presently working as Assistant Professor in the Department of Basic and Applied Sciences, Punjabi University, Patiala, Punjab, India. She has been pursuing research on fabrication, characterization and application of nanomaterials since 2003 .

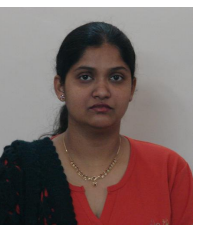

